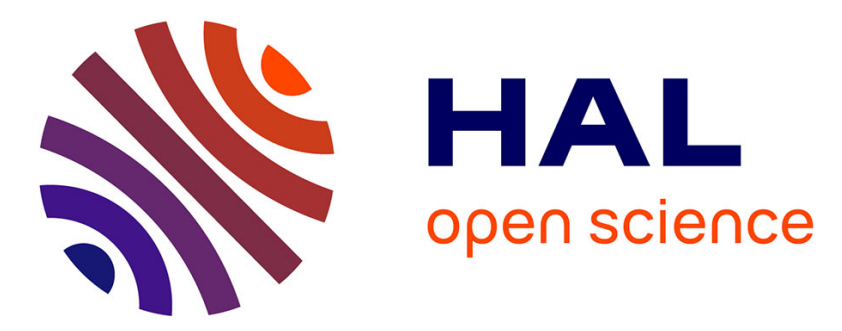

\title{
Bauschinger Effect in an Austenitic Steel: Neutron Diffraction and a Multiscale Approach
}

Jamal Fajoui, David Gloaguen, Vincent Legrand, Guy Oum, Joe Kelleher, Winfried Kockelmann

\section{- To cite this version:}

Jamal Fajoui, David Gloaguen, Vincent Legrand, Guy Oum, Joe Kelleher, et al.. Bauschinger Effect in an Austenitic Steel: Neutron Diffraction and a Multiscale Approach. Metallurgical and Materials Transactions A, 2016, 47 (5), pp.2024-2036. 10.1007/s11661-016-3362-5 . hal-01831093

\section{HAL Id: hal-01831093 https://hal.science/hal-01831093}

Submitted on 5 Jul 2018

HAL is a multi-disciplinary open access archive for the deposit and dissemination of scientific research documents, whether they are published or not. The documents may come from teaching and research institutions in France or abroad, or from public or private research centers.
L'archive ouverte pluridisciplinaire HAL, est destinée au dépôt et à la diffusion de documents scientifiques de niveau recherche, publiés ou non, émanant des établissements d'enseignement et de recherche français ou étrangers, des laboratoires publics ou privés. 


\title{
Bauschinger Effect in an Austenitic Steel: Neutron Diffraction and a Multiscale Approach
}

\author{
JAMAL FAJOUI, DAVID GLOAGUEN, VINCENT LEGRAND, GUY OUM, \\ JOE KELLEHER, and WINFRIED KOCKELMANN
}

The generation of internal stresses/strains arising from mechanical deformations in single-phase engineering materials was studied. Neutron diffraction measurements were performed to study the evolution of intergranular strains in austenitic steel during sequential loadings. Intergranular strains expand due to incompatibilities between grains and also resulting from single-crystal elastic and plastic anisotropy. A two-level homogenization approach was adopted in order to predict the mechanical state of deformed polycrystals in relation to the microstructure during Bauschinger tests. A mechanical description of the grain was developed through a micro-meso transition based on the Krö ner model. The meso-macro transition using a self-consistent approach was applied to deduce the global behavior. Mechanical tests and neutron diffraction measurements were used to validate and assess the model.

\section{INTRODUCTION}

ONE of the major issues in materials engineering is to satisfy requirements for the manufacturing of mechanical structures made of damage-resistant alloys. Engineering processes create defects at the surface and / or localized in the mechanical piece. These defects are characterized by cracks, micro-cracks and residual stresses which result in fast or slow damage of the mechanical parts during service. The choice of the alloy allows making the material more or less ductile to resist the various mechanical loadings.

A better understanding of the mechanical properties of alloys and the prediction of those properties lead to optimization of manufacturing processes and cost reductions. Understanding the relationships between the microstructure and the mechanical properties is very important for this. Several experimental and theoretical works were done in recent decades to identify and describe realistically the main physical mechanisms observed in metallic materials. Many studies were performed on plasticity mechanisms, as dislocation microstructure, leading to the development of a crystal plasticity approach. Therefore, the homogenization approach was developed to predict the macroscopic behavior by linking the different physical mechanisms to the material behavior.

JAMAL FAJOUI, Assistant Professor, DAVID GLOAGUEN, Professor, VINCENT LEGRAND, Assistant Professor, and GUY OUM, Doctor, are with the Université de Nantes, Institut de Recherche en Génie Civil et Mécanique (UMR CNRS 6183), 58, rue Michel Ange, BP 420, 44606 Saint-Nazaire Cedex, France. Contact e-mail: jamal.fajoui@univ-nantes.fr JOE KELLEHER and WINFRIED KOCKELMANN, Doctors, are with the ISIS Facility, Science and Technology Facilities Council, Rutherford Appleton Laboratory, Harwell Oxford Didcot, Oxfordshire, OX11 0QX, England.
This kind of approach aims to deduce the macroscopic properties of materials from the characterization and analysis of their microstructure and their deformation mechanisms. This methodology is based on a combined transition level approach and experimental analysis. $^{[1]}$ Characterizations and mechanical validations (mechanical tests, diffraction analysis...) are performed at the local and macroscopic levels linked to the definition of the representative elementary volume (REV). Thus, it is necessary to define the suitable scale of basic volume (BV) or the element of REV. Therefore, the analysis of activated mechanisms allows the implementation of a multiscale method so as to determine the macroscopic behavior. Depending on the type of studied materials and the intended applications, the considered BV has to be different. For a polycrystalline aggregate, the grain represents the starting scale also called BV. According to its orientation, each grain has a different behavior related to the crystallographic nature of the strain mechanisms.

In the monotonic loading cases, polycrystalline approaches such as self-consistent models give results in agreement with experimental observations as in the cases of hardening, texture evolution and internal strain. ${ }^{[2]}$

However, these models remain weak in the case of changing path loading as Bauschinger tests in which the second load is poorly described (yield stress, strain hardening). This is because some physical phenomena are not taken into account at the grain scale during plasticity with a more realistic description. The formation of a dislocation microstructure, responsible for intragranular heterogeneities, is insufficiently represented through hardening laws. ${ }^{[3]}$

In this case, the modelling effort must be focused on the description of grains interactions and their local behavior. If the intergranular heterogeneities prevail at 
low and monotonic loading, they gradually give rise to intragranular heterogeneities during complex loading. ${ }^{[4,5]}$ On the other hand, analysing the Bauschinger effect would be better to predict the mechanical behavior for fatigue tests. In fact, the dislocation microstructure, appearing during the first sequential loadings (tensile-compression for example), has significant influence on materials lifetime. ${ }^{[6-8]}$

Recently, several studies were carried out to develop models which incorporate the effects of dislocation microstructure on the global and local mechanical response of a metallic material. ${ }^{[9-12]}$ The first attempt to model the dislocation structure was proposed by Mughrabi ${ }^{[13]}$ who introduced an approach in which the grain was considered as a composite consisting of hard dislocation walls (with high local dislocation density) separated by soft regions (with low local dislocation density). Peeters et al. ${ }^{[1,15]}$ developed a semi-phenomenological crystal plasticity approach that incorporates more details of microstructural evolution at the grain scale (evolution of dislocation densities) and used a full-constraint Taylor model to describe the behavior of body-centered cubic structure polycrystals (BCC). Karaman et al. ${ }^{[16]}$ used a similar approach and successfully modelled the deformation of Hadfield steel with a viscoplastic self-consistent (VPSC) scheme. Viatkina et al. ${ }^{[17]}$ used a micromechanical model of dislocation cell structure accounting for the material inhomogeneity and incorporated the internal stresses.

Knezevic et al. ${ }^{[18]}$ implemented the VPSC polycrystalline model in an implicit finite element (FE) framework, accounting for a dislocation-based hardening law for multiple slip and twinning modes at the grain level. Their model was applied to simulate the macroscopic mechanical response of a highly anisotropic low-symmetry (orthorhombic) crystal structure. Franz et al. ${ }^{[19]}$ adopted advanced large-strain elastoplastic single-crystal constitutive modelling, accounting for the main physical mechanisms that are relevant at the microscale. They have used the self-consistent scale scheme which was then used to derive the overall constitutive response of polycrystalline aggregates, including the essential microstructural aspects (e.g., initial and induced textures, dislocation density evolution and softening mechanisms). Saleh et al. ${ }^{[1]}$ took into account the pronounced Bauschinger effect observed upon reversal load by a combination of the intergranular residual stresses and the intragranular sources of back stress, such as dislocation pile-ups at the intersection of stacking faults. This study was investigated on a twinning-induced plasticity (TWIP) steel via in situ neutron diffraction during cyclic loadings (tension-compression) between strain limits of \pm 1 pct.

A composite model was employed to describe the material with its dislocation cell structure. ${ }^{[4,5,13,20,21]}$ This approach was successfully applied to predict the macroscopic behavior of face-centered cubic crystal structure (FCC) alloys after various strain path changes. The concept of non-local hardening (the yield stress of the walls increases with the plastic strain of the cells) related to the two-phase cells structure was introduced, for the first time, by Muller et al ${ }^{[4,5]}$ and developed later by Lemoine et al. ${ }^{[21,22]}$ with a two-scale homogenization based on a polycrystalline model. The morphology of the dislocation structure was taken into account by the authors. The different numerical results concerning complex path loads show a better description of the influence of the dislocation structure.

In previous works, ${ }^{[3,23]}$ based on the approach originally proposed by Muller et al., ${ }^{[4,5]}$ the present authors have extended the elastoplastic self-consistent model (EPSC) by incorporating more details of the microstructure at the grain scale. The grain was considered as a two-phase material (dislocation walls and cells). Dislocation densities on each slip system were considered as internal variables and a hardening matrix, taking account the different dislocations interactions, was proposed.

A micro-mechanical description of a single crystal was developed through a micro-mesoscopic transition using Kröner ${ }^{[23]}$ and self-consistent ${ }^{[3]}$ approaches. Therefore, the grain behavior was calculated from phases (cell and wall). In addition, a meso-macroscopic transition, using the EPSC method, ${ }^{[24]}$ was applied to deduce the macroscopic response of the FCC aggregate. The simulations based on the developed model demonstrated its ability to predict the experimental response of the observed material after moderate strain-path changes. To validate their approaches, the present authors used experimental results from the literature. ${ }^{[25-27]}$

In this work, a two-level homogenization approach was developed for the micromechanical modelling of the elastoplastic material behavior. ${ }^{[23]}$ This study is particularly devoted to sequential loadings. At the microscopic scale, the mechanical behavior is described by the Kröner's model. The grain is considered as a two-phase material: dislocations walls (with high density dislocation) and cells (with low density dislocation). The intragranular heterogeneities are highlighted by a non-local work-hardening, which is linked to the two-phase description. In this model, the dissolution of the dislocation microstructure observed during the second loading is implemented. At the global scale, the mechanical behavior is deduced from the mesoscopic one by an EPSC model. To validate our numerical approach and explain the Bauschinger mechanisms, a confrontation between simulation results and neutron diffraction (ND) experimental data ends this paper. This will allow getting a complete analysis at different levels: from the diffraction volume scale to the macroscopic one.

\section{EXPERIMENTAL PROCEDURE}

The material used in the present work is a standard $316 \mathrm{~L}$ austenitic steel alloy. Its chemical composition is given in Table I. The cylindrical samples were $8 \mathrm{~mm}$ in diameter and $14 \mathrm{~mm}$ high.

The initial residual stresses were determined in a non-deformed sample with a four circles XRD 3003 PTS SEIFERT goniometer using $\mathrm{K}_{\alpha}$ chromium radiation with a $0.5 \mathrm{~mm}$ diameter collimator. The diffraction peaks, corresponding to (220) plane, were collected by a 
Table I. Chemical Composition of a Standard 316L Austenitic Steel Alloy

\begin{tabular}{llllll}
\hline C (Pct) & Si (Pct) & Mn (Pct) & P (Pct) & S (Pct) & Cr (Pct) \\
0.015 & 0.31 & 1.44 & 0.028 & 0.021 & 16.51 \\
Ni (Pct) & Mo (Pct) & Cu (Pct) & N (Pct) & Co (Pct) & Fe (Pct) \\
10.46 & 2.13 & 0.18 & 0.02 & 0.04 & 68.84 \\
\hline
\end{tabular}

position sensitive detector for the azimuths $\varphi=0 \mathrm{deg}$, $45 \mathrm{deg}$ and $90 \mathrm{deg}$ with 16 tilt angles ranging from -48 deg to $45 \mathrm{deg}$. The set of diffraction peaks obtained for all incidence angles have been fitted with a pseudo-Voigt function taking into account the $\mathrm{K}_{\alpha 1}-\mathrm{K}_{\alpha 2}$ contribution. The centroid of the fitted diffraction line was taken as the peak position. For each diffraction peak, background was fitted through a polynomial function. The measurement ranges were chosen in order to cover an adequate number of points for a complete description of peak tails and background. The counting times and step size were adjusted to obtain a sufficient peak-to-background ratio for an accurate peak position determination. Using Bragg's law, the interplanar spacing was calculated from diffraction peak displacements. The standard $\sin ^{2} \psi$ method was used for the determination of the residual stress tensor. The diffraction elastic constants $1 / 2 S_{2}$ and $S_{1}$ were theoretically calculated with an elastic self-consistent model. ${ }^{[28]}$ The initial residual stresses determined by XRD in the non-deformed sample were introduced into the model as the starting grain stresses for simulation calculations. Appropriate boundary conditions were applied to model the mechanical loading at the strain state corresponding to the neutron diffraction measurements that were performed. Due to the presence of initial residual stresses, the predicted lattice strains are not equal to zero for the non-deformed material. For a direct comparison with experimental strains measured by neutron diffraction, the relative strains corresponding to the applied stresses and defined by Eq. [1] were calculated. ${ }^{[29,30]}$

In order to analyse the lattice strains in the bulk sample, we used the ENGIN-X beamline at the ISIS facility, Rutherford Appleton Laboratory (Didcot, UK), using a $50 \mathrm{kN}$ Instron testing rig. Briefly, the ENGIN-X instrument presents a horizontal loading axis composing a 45 deg angle with the incident beam ${ }^{[31]}$ (Figure 1). Two detector banks are set up at angles \pm 90 deg to the incident beam, allowing simultaneous measurements of lattice strains in both parallel (loading direction, denoted LD, and perpendicular (transverse direction, TD) directions to the applied load, in the opposing 90 deg detector banks. The detector banks cover $\pm 14 \mathrm{deg}$ in the horizontal plane and $\pm 21 \mathrm{deg}$ in the vertical one. ${ }^{[31]}$ ENGIN-X measurements are performed on the basis of time-of-flight technics (TOF). The incident beam coming from the source is split into neutrons bunches thanks to a chopper rotating at a specific frequency. Each bunch is thus constituted with neutrons having different energies (i.e., different wavelengths) and so different velocities. It means that neutrons, from the same bunch, will cover the distance [source - instrument (sample) - detector] in a distinct time depending of their velocity. Then, measured data

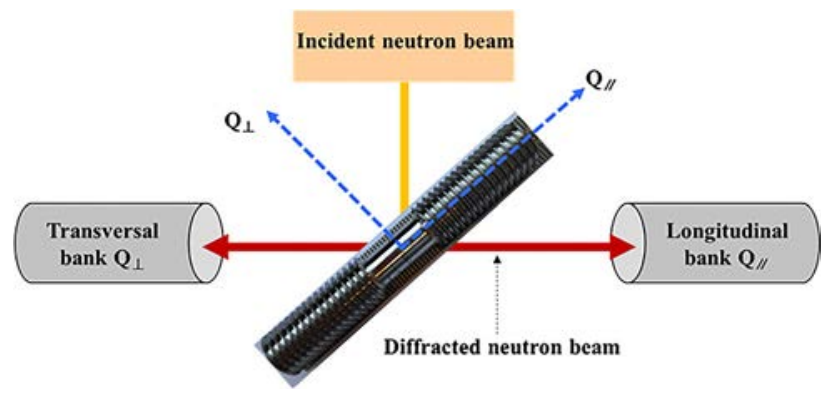

Fig. 1-Schematic view of the ENGIN-X neutron diffraction instrument (ISIS facility, UK) showing the interaction between the incident neutron beam and the studied material, giving rise to two diffracted beams. The two detector banks of the ENGIN-X instrument, placed at 90 deg on either side of the sample in relation to the incident beam, can measure simultaneously the longitudinal and transverse deformations.

can be analysed using the TOF method, as neutrons are collected as a function of their propagation times or TOF (i.e., as a function of their energies) and not as a function of the Bragg angle $\theta_{\mathrm{hkl}}$. As the measured TOF depends of the neutron wavelength, the Bragg law can be expressed with $d_{\mathrm{hkl}}=\frac{h}{2 m_{\mathrm{n}} L \sin \left(\theta_{\mathrm{hkl}}\right)}$, where dhkl is the interplanar distance in $\AA, h$ is the Planck constant, $m_{\mathrm{n}}$ is the neutron mass, $L$ is the neutron source to detector covered distance and $\theta_{\mathrm{hkl}}$ the Bragg angle. A consequence of the TOF technics is that the whole diffraction pattern (effective $d$-spacing range from 0.88 to $2.63 \AA$ ) can be collected in a single neutron detector and the diffraction patterns expressed the diffracted intensity versus TOF (in $\mu \mathrm{s}$ ) or based on the interplanar distance $d_{\mathrm{hk} 1}(d$-spacing, in angstroms).

The gauge volume was $4 \times 4 \times 4 \mathrm{~mm}^{3}$, and the recording time was taken over 15 minutes for each measurement at a given macroscopic strain. Macroscopic strain was monitored on the sample using a clip gauge. Peak fitting was performed using the Open Genie code. ${ }^{[32]}$

Single peak fitting enables following the answer of individual lattice reflections hkl to deformation and thus directly provides information on intergranular effects. Changes in individual peak positions during deformation as returned from single peak fitting were used to calculate the $\{h \mathrm{kl}\}$ specific lattice strains $\langle\varepsilon(\mathrm{hkl})\rangle_{\mathrm{VD}}$ using:

$$
\langle\varepsilon(\mathrm{hkl})\rangle_{\mathrm{VD}}=\frac{\langle d(\mathrm{hkl})\rangle_{\mathrm{VD}}-d_{0}(\mathrm{hkl})}{d_{0}(\mathrm{hkl})}
$$

where $d(\mathrm{hkl})$ is the $d$-spacing for the deformed material and $d_{0}(\mathrm{hkl})$ corresponds to the initial $d$-spacing without any applied stress (non-deformed material). 


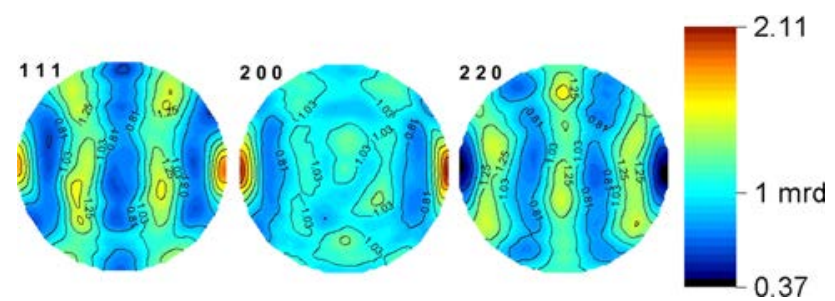

Fig. 2-Initial experimental pole figure of $316 \mathrm{~L}$ austenitic steel obtained using MAUD software. ${ }^{[51]}$

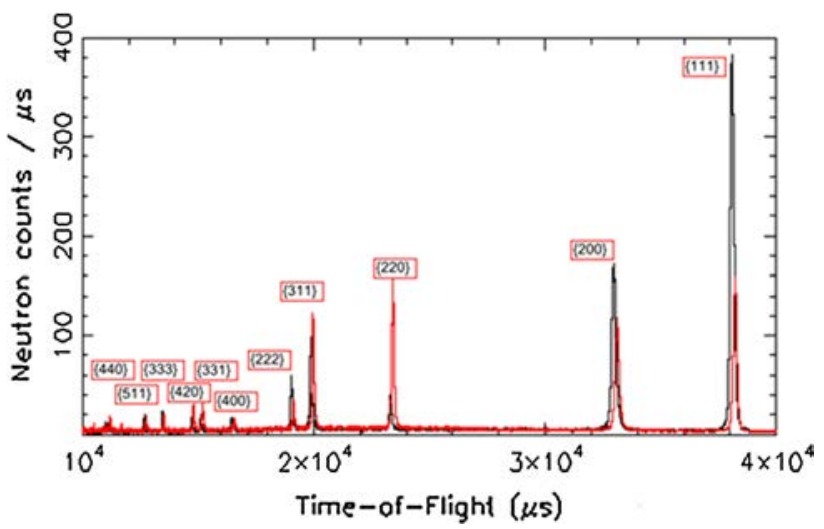

Fig. 3-Typical neutron diffraction patterns obtained in the longitudinal (black line) and transverse (red line) detectors, acquired on the ENGIN-X beamline.

The reference point for this calculation is the initial measured $\mathrm{d}_{0}(\mathrm{hkl})$ for each lattice plane before deformation of the material. \langle\rangle$_{\mathrm{VD}}$ is the average over diffracting grains for the considered hkl reflection. Throughout the paper, the lattice strain is presented in units of microstrain $(\mu \varepsilon)$, where $1 \mu \varepsilon=10^{-6}$.

Texture measurements were performed at the GEM beamline at the ISIS facility. Detailed information about the instrument and the technique used to determine the texture, can be found in Reference 33. Figure 2 shows the initial texture for three crystallographic reflections highlighting that the material is nearly isotropic.

Tension-compression tests were performed at room temperature. We considered two pre-strains: 2 and 6 pct in tension mode for the first test, and, -2 and -3 pct in compression mode for the second one.

In situ volume analyses were used in order to follow the evolution of internal strains during tension-compression tests at different macroscopic deformation rates with an interval of 0.5 pct. Experimental data were measured and analysed for several crystallographic planes families (Figure 3). Only statistically representative hkl peaks in relation to the measured intensity are discussed in the following; i.e., 111, 200, 220 and 311.

\section{TWO-LEVEL HOMOGENIZATION APPROACH}

During Bauschinger test, it should be important to explain more realistically the overall behavior from the evolution of dislocation microstructure. As described in the literature, ${ }^{[34,35]}$ when a material undergoes a load beyond the elastic limit, a plastic mechanism quickly starts up, characterized by the creation and the movement of dislocation structure within the grain and along a given slip system. The appearance of dislocations in two regions comes with this mechanism:

(i) cells with low dislocation density;

(ii) walls with high dislocation density coming with the increasing plastic strain.

The evolution of dislocation density is not similar in cells and walls. Consequently, a strong internal stress gradient, with a higher one in the walls than in the cells, is created. This generated composite medium, with contrasting mechanical properties, is characterized by a shape and an orientation which result mainly from an overall effect of loading on the polycrystal. As a consequence of changing the path load, this microstructure evolves and becomes sensitive during elastoplastic transitions. Moreover, the microstructure is able to bring about the occurrence of destabilizing microband shear. Therefore, the material damage is started. This explains the importance of developing a micromechanical approach that better takes into account the dislocation microstructures. A more realistic material behavior could be simulated during sequential loadings thanks to the incorporation of intragranular heterogeneities.

In this section, we detail the model used to describe the mechanical behavior of a FCC polycrystal aggregate based on a two-level homogenization approach (Figure 4). Each grain is treated as a two-phase composite (heterogeneous medium) with dislocations walls and cells. ${ }^{[13]}$ In each phase, it is assumed that slip is the predominant deformation mechanism and that Schmid's law is valid. The elastic behavior of both phases is assumed to be the same. The Kröner model ${ }^{[36]}$ is based on the solution of an ellipsoidal inclusion representing a given phase, embedded in a homogeneous equivalent medium (HEM). The consistency conditions (global compatibility and equilibrium) require that the average of the local fields within grain volume should be equal to the mesoscopic imposed ones. These averages express the fields of the HEM. The Kröner formulation allows each phase to deform independently and differently, according to its properties and depending on the strength of the interaction between the phase and its surroundings (via the Eshelby tensor). In this view, each phase is in turn considered as an ellipsoidal inclusion surrounded by a HEM which has the average properties of the grain. It should be noticed that the phase state is characterized by the initial shape and orientation of the ellipsoid corresponding to a phase. The interaction between the inclusion and the HEM is solved by means of the Eshelby formalism. The HEM properties are not known in advance, but have to be calculated considering the average of the individual phase behavior. The presented model is formulated under the assumption of small deformation theory. 


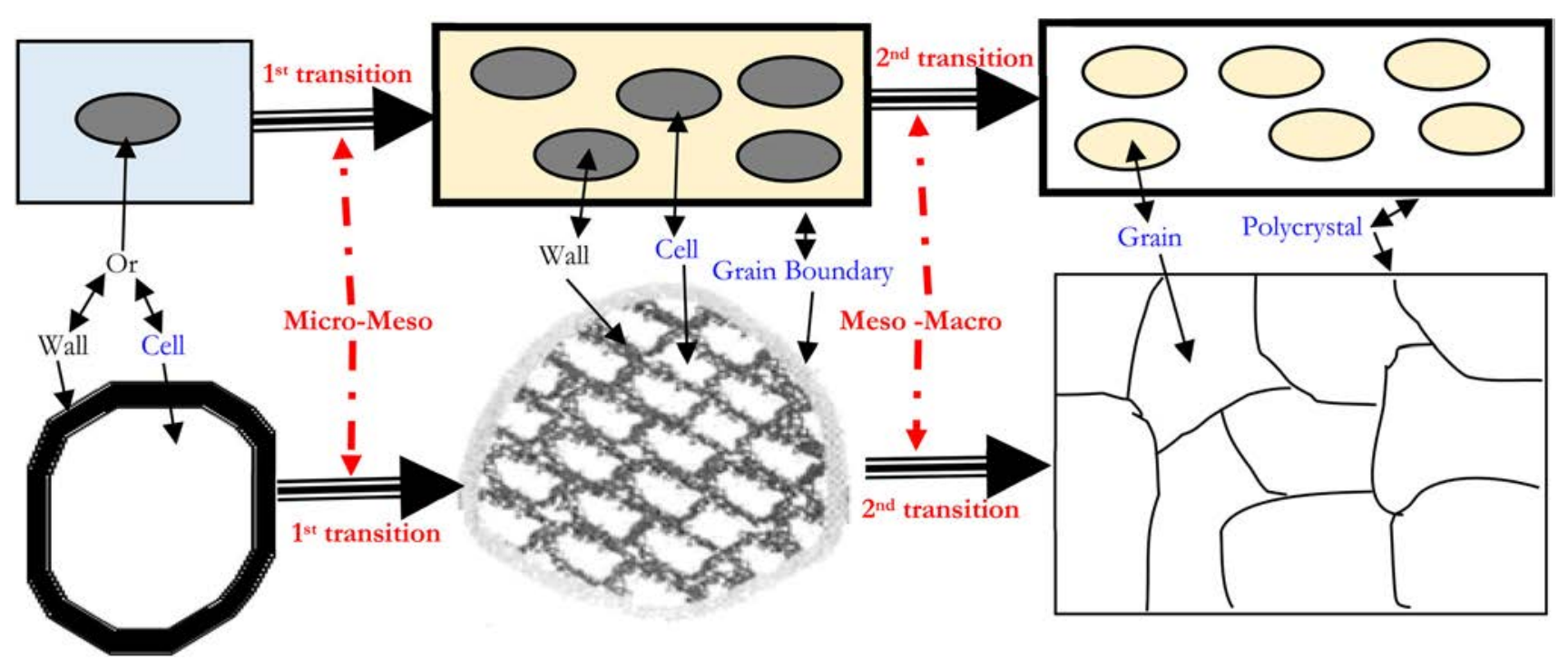

Fig. 4-Schematic diagram explaining the two-level homogenization approach.

The EPSC approach is adopted to perform the second transition level (from grain to polycrystal). In the present work, the model developed in Reference 24 is used. For more details of the EPSC model, see References 37, 38. For the simulation, the polycrystal is assumed to be made up of single crystals which orientations are specified by a set of discrete Euler angles weighted to reproduce the crystallographic texture shown in Figure 2. Each grain is considered as an elastoplastic anisotropic ellipsoidal inclusion embedded within a homogenous effective medium (HEM). The response and properties of the HEM are calculated as a weighted average of all single crystals.

\section{A. First Transition Scheme}

The phases have the same isotropic elastic behavior described by shear modulus $\mu$ and Poisson's ratio $v$. The grain undergoes a strain $\varepsilon^{\mathrm{II}}$ (with a stress $\sigma^{\mathrm{II}}$ ) composed of an elastic part $\varepsilon^{\mathrm{e}}$ and a plastic one $\varepsilon^{\mathrm{p}}$. Describing by $\varepsilon^{\mathrm{pc}}$ and $\varepsilon^{\mathrm{pw}}$ the mean plastic strain in the dislocation cells (c) and walls $(w)$ respectively, one can write as follows:

$$
\varepsilon^{I I}(\Omega)=(1-f) \varepsilon^{\mathrm{w}}(\Omega)+f \varepsilon^{\mathrm{c}}(\Omega)
$$

where $f_{\mathrm{c}}$ (respectively $f_{\mathrm{w}}=1-f_{\mathrm{c}}$ ) is the inner volume fraction of cell (respectively cell walls) in a grain. $\Omega$ stands for the specific orientation of the considered inclusion in the specimen reference. $\Omega$ represents a vector in the three-dimensional crystallographic orientation; $\Omega=\left(\varphi_{1}, \phi, \varphi_{2}\right)$, where $\varphi_{1}, \phi$, and $\varphi_{2}$ are the Euler angles. In the remainder, $\Omega$ is omitted in order to lighten equations.

Using the same mixture rule for stress, one has

$$
\sigma^{I I}=(1-f) \sigma^{\mathrm{w}}+f \sigma^{\mathrm{c}}
$$

where $\sigma^{\alpha}$ corresponds to the stress tensor in the phase $\alpha$ (the superscript ' $w$ ' stands for walls and ' $c$ ' for cells) and $\sigma^{\mathrm{II}}$ is the stress tensor induced in the grain.
With an isotropic elastic behavior:

$$
\varepsilon^{\mathrm{p} I I}=(1-f) \varepsilon^{\mathrm{pw}}+f \varepsilon^{\mathrm{pc}}
$$

Using the Eshelby's works, Kröner ${ }^{[36,39]}$ was adapted to the case of a two-phase composite:

$$
\sigma^{\alpha}=\sigma^{I I}+\alpha_{\mathrm{T}} c^{\alpha}:\left(I-s^{\mathrm{esh}}\right):\left(\varepsilon^{\mathrm{pw}}-f_{\varepsilon^{\mathrm{p} \alpha}}\right)
$$

where $I$ represents the fourth order identity tensor. $c^{\alpha}$ is the elastic constant tensor for the phase $\alpha$. It is assumed that the same isotropic elastic parameters are used in both phases $\left(c^{\alpha}=c^{\mathrm{w}}=c^{\mathrm{c}}\right)$.

The Eshelby tensor, $s^{\text {esh }}$, expresses inclusion interaction, with a given morphology independently of its elastic properties. The tensor $s^{\text {esh }}$ is evaluated basing on elastic properties of the matrix and the mechanical predicted behavior will be too stiff. One may retain the convenience of Kröner's treatment but making a useful assumption of plastic accommodation proposed by Reference 40. An accommodation factor $\alpha_{\mathrm{T}}$ is introduced. This crude but simple and efficient approximation allows simulating quite well the mechanical response of real metals. This factor is used with an additional assumption concerning $\alpha_{\mathrm{T}}$ : it is supposed independent of the plastic flow and $\alpha_{\mathrm{T}}=1 / 10 .{ }^{[41]}$ In the following and for more clarity, the factor $\alpha_{\mathrm{T}}$ is omitted.

Taking into account the relations [2], [3] and [4], the mean stress tensors $\sigma^{\mathrm{c}}$ and $\sigma^{\mathrm{w}}$ within the cells and the walls can be written as

$$
\begin{gathered}
\sigma^{\mathrm{c}}=\sigma^{I I}+(1-f) c:\left(I-s^{\mathrm{esh}}\right):\left(\varepsilon^{\mathrm{pw}}-f \varepsilon^{\mathrm{pc}}\right) \\
\sigma^{\mathrm{w}}=\sigma^{I I}+f c:\left(I-s^{\mathrm{esh}}\right):\left(\varepsilon^{\mathrm{pw}}-f \varepsilon^{\mathrm{pc}}\right)
\end{gathered}
$$

The plastic strain rate for each phase is the following: 


$$
\dot{\varepsilon}^{\mathrm{p} \alpha}=\sum_{\mathrm{g}} R_{\alpha}^{\mathrm{g}} \dot{\gamma}_{\alpha}^{\mathrm{g}}
$$

where $R_{\alpha}^{\mathrm{g}}$ is the Schmid tensor on a system $g . \dot{\gamma}_{\alpha}^{\mathrm{g}}$ denotes the slip rate on a system $g$.

The elastic strain rate is linked to the stress rate in the grain through the Hooke's law:

$$
\dot{\varepsilon}^{e I I}=\dot{\varepsilon}^{I I}-\dot{\varepsilon}^{\mathrm{p} I I}=s: \dot{\sigma}^{I I}
$$

where $s$ is the elastic compliance tensor at the grain level. The symbol “:” denotes a contracted tensor product.

The main mechanism responsible, for the hardening, involves dislocations that generate inside grains and build a particular architecture. ${ }^{[23]}$ Few dislocations accumulate within cells. The annihilation of dislocations is mainly localized inside walls due to the rearrangement of dislocations associated with the plastic strain inside walls. ${ }^{[42]}$ Basing on these physical processes and using the work of Essman and Mughrabi, ${ }^{[43]}$ the rate of increase of dislocation density inside the walls on the system $g$ is

$$
\dot{\rho}_{\mathrm{w}}^{\mathrm{g}}=\dot{\rho}_{\mathrm{w}}^{\mathrm{g}+}+\dot{\rho}_{\mathrm{w}}^{\mathrm{g}-}
$$

with:

$$
\dot{\rho}_{\mathrm{w}}^{\mathrm{g}+}=\frac{1}{b L^{\mathrm{g}}} \dot{\gamma}_{\mathrm{c}}^{\mathrm{g}} \quad \text { and } \quad \dot{\rho}_{\mathrm{w}}^{\mathrm{g}-}=-\frac{2 y_{\mathrm{c}}}{b} \rho_{\mathrm{w}}^{\mathrm{g}} \dot{\gamma}_{\mathrm{w}}^{\mathrm{g}}
$$

$\dot{\rho}_{\mathrm{w}}^{\mathrm{g}+}$ corresponds to the rate of increase of dislocation density inside the walls on the system $\mathrm{g}$. This term is responsible for the creation and the development of the cell structure. This flux consists in dislocations that glide towards walls through the applied stress.

$\dot{\rho}_{\mathrm{W}}^{\mathrm{g}-}$ is the annihilation term which takes into account the dynamic recovery during the deformation.

$b$ is the magnitude of the Burgers vector and $y_{\mathrm{c}}$ is proportional to the annihilation distance of dislocation dipoles. $L^{\mathrm{g}}$ is the mean free path of mobile dislocations in the cell interiors associated to the deformation system $g$. Its evolution is managed by the density of point obstacles (essentially cell walls) cutting the system $g$ and creating interactions with gliding dislocations. Therefore,

$$
L^{g}=\frac{k_{L}}{\sqrt{\sum_{h \neq g} \rho_{w}^{h}}}
$$

The critical resolved shear stress (CRSS) can be related to the dislocation densities by the hardening relation: ${ }^{[44]}$

$$
\tau_{\mathrm{c} \alpha}^{\mathrm{g}}=\tau_{\mathrm{c} 0 \alpha}^{\mathrm{g}}+\xi \mu b \sqrt{\sum_{\mathrm{h}} a^{\mathrm{gh}} \rho_{\alpha}^{\mathrm{h}}}
$$

$\tau_{\mathrm{c} 0 \alpha}^{\mathrm{g}}$ is the initial reference shear stress on system $\mathrm{g}$ and $\xi$ is a constant depending on the interaction of dislocations. According to, ${ }^{[44]} a^{\text {gh }}$ is a hardening matrix which terms depend on the type of interactions between slip systems $g$ and $h$. Only two terms, $a^{\mathrm{gg}}$ and $a_{\mathrm{g} \neq \mathrm{h}}^{\mathrm{gh}}$ (respectively self- and latent hardening parameters), will be considered. $\rho_{\alpha}^{h}$ is the dislocation density in the phase $\alpha$.

During plastic strain, dislocations, generated inside cells, move and store in walls. Hence, the cell structure affects the wall. This is the non-local hardening concept introduced by Muller et al. ${ }^{[4]}$ In the general case, the non-local hardening laws can be written for a two-phase composite as follows: ${ }^{[4]}$

$$
\begin{gathered}
\dot{\tau}_{c c}^{g}=\sum_{h} H_{c c}^{g h} \dot{\gamma}_{c}^{h}+\sum_{h} H_{c w}^{g h} \dot{\gamma}_{w}^{h} \quad \text { and } \\
\dot{\tau}_{c w}^{g}=\sum_{h} H_{w c}^{g h} \dot{\gamma}_{c}^{h}+\sum_{h} H_{w w}^{g h} \dot{\gamma}_{w}^{h}
\end{gathered}
$$

$H_{\mathrm{cc}}^{\mathrm{gh}}, H_{\mathrm{ww}}^{\mathrm{gh}}, H_{\mathrm{cw}}^{\mathrm{gh}}$ and $H_{\mathrm{wc}}^{\mathrm{gh}}$ are the hardening matrices describing interactions between dislocations moving on various slip systems. $H_{\mathrm{cc}}^{\mathrm{gh}}$, and $H_{\mathrm{ww}}^{\mathrm{gh}}$ describe the influence of a system $\mathrm{h}$ on another deformation system $\mathrm{g}$ for a given phase. $H_{\mathrm{cw}}^{\mathrm{gh}}$ and $H_{\mathrm{wc}}^{\mathrm{gh}}$ stand for the non-local hardening and the influence of one phase on the other one. For an appropriate representation of the hardening behavior, these matrices are expressed with microstructural variables such as dislocation density. By combining the previous Eqs. [9] through [14], the work-hardening matrices $H_{\mathrm{ww}}^{\mathrm{gh}}$ and $H_{\mathrm{wc}}^{\mathrm{gh}}$ become

$$
H_{\mathrm{ww}}^{\mathrm{gh}}=-\frac{y_{\mathrm{c}} \xi^{2} \mu^{2} b}{\left(\tau_{\mathrm{cw}}^{\mathrm{g}}-\tau_{\mathrm{c} 0 \mathrm{w}}^{\mathrm{g}}\right)} \rho_{\mathrm{w}}^{\mathrm{h}} a^{\mathrm{gh}} \quad \text { and } \quad H_{\mathrm{wc}}^{\mathrm{gh}}=\frac{\xi^{2} \mu^{2} b}{2\left(\tau_{\mathrm{cw}}^{\mathrm{g}}-\tau_{\mathrm{c} 0 \mathrm{w}}^{\mathrm{g}}\right)} \frac{a^{\mathrm{gh}}}{L^{\mathrm{h}}}
$$

Because of the low accumulation of dislocations inside cells, $H_{\mathrm{cc}}^{\mathrm{gh}}$ is simply described by a constant. The influence of walls on the evolution of dislocations in cells can be considered as negligible. Finally,

$$
H_{\mathrm{cc}}^{\mathrm{gh}}=\frac{\varsigma}{\tau_{\mathrm{cw}}^{\mathrm{g}}-\tau_{\mathrm{c} 0 \mathrm{w}}^{\mathrm{g}}} a^{\mathrm{gh}} \quad \text { and } \quad H_{\mathrm{cw}}^{\mathrm{gh}}=0
$$

During the plastic regime, the variation of the cell interior volume fraction for a grain $\mathrm{I}$ is considered as a function of the accumulated slips through the following empiric relation: ${ }^{[22]}$

$$
f_{\mathrm{cn}}=f_{\infty}+\left(f_{0}-f_{\infty}\right) \exp \left(-\frac{\gamma_{\mathrm{cn}}^{\mathrm{acc}}}{\gamma^{\mathrm{par}}}\right)
$$

where $f_{0}$ is the initial volume fraction and $f_{\infty}$ is the saturation value at large strains. $\gamma^{\text {par }}$ is a parameter describing the decrease rate of $f_{\mathrm{cn}}$ and $\gamma_{\mathrm{cn}}^{\mathrm{acc}}$ is the accumulated slip in the cell in the grain $n$. This relation allows taking into account the intergranular plastic heterogeneities. The volume fraction of cells for each crystallite develops differently in relation to the effect of the grain orientation. It only depends on the plasticity activity. In the remainder, the cell volume fraction will be denoted $f_{\mathrm{c}}$ instead of $f_{\mathrm{cn}}$.

The plastic flow can take place in a grain when the Schmid criterion is checked, i.e., slip occurs if the resolved shear stress $\tau_{\alpha}^{\mathrm{g}}$ on a system $\mathrm{g}$, for each phase, is 
equal to the critical value $\tau_{\mathrm{c} \alpha}^{\mathrm{g}}$ depending on the hardening state of the slip system. This necessary but insufficient condition requires complementary assumption which states that the increment of the resolved shear stress must be equal to the incremental rate of the CRSS. The resolved shear stress is defined as the projection of the phases stress tensor $\sigma^{\alpha}$ on the considered deformation system. For small strain formulation, it follows:

$$
\tau_{\alpha}^{\mathrm{g}}=R_{\alpha}^{\mathrm{g}}: \sigma^{\alpha}=\tau_{\alpha}^{\mathrm{g}} \quad \text { and } \quad \dot{\tau}_{\alpha}^{\mathrm{g}}=R_{\alpha}^{\mathrm{g}}: \dot{\sigma}^{\alpha}=\dot{\tau}_{\alpha}^{\mathrm{g}}
$$

The Schmid criterion is thus given by

$$
\begin{gathered}
\tau_{\alpha}^{\mathrm{g}}<\tau_{\mathrm{c} \alpha}^{\mathrm{g}} \Rightarrow \dot{\gamma}_{\alpha}^{\mathrm{g}}=0 \\
\tau_{\alpha}^{\mathrm{g}}=\tau_{\mathrm{c} \alpha}^{\mathrm{g}} \text { and } \quad \dot{\tau}_{\alpha}^{\mathrm{g}}<\dot{\tau}_{\mathrm{c} \alpha}^{\mathrm{g}} \Rightarrow \dot{\gamma}_{\alpha}^{\mathrm{g}}=0 \\
\tau_{\alpha}^{\mathrm{g}}=\tau_{\mathrm{c} \alpha}^{\mathrm{g}} \quad \text { and } \quad \dot{\tau}_{\alpha}^{\mathrm{g}}=\dot{\tau}_{\mathrm{c} \alpha}^{\mathrm{g}} \Rightarrow \dot{\gamma}_{\alpha}^{\mathrm{g}}>0
\end{gathered}
$$

The main problem is to determine which combination of slip systems will actually be activated at each step of the plastic deformation path. In this case, all possible combinations of potentially active systems must be scanned to find at least one that satisfies the two

$$
\begin{gathered}
K_{\alpha}^{\mathrm{g}}=\frac{1}{H_{\alpha \alpha}^{\mathrm{gg}}}\left[\frac{1}{2}\left(1+\operatorname{Tanh}\left(k\left(\frac{\tau_{\alpha}^{\mathrm{g}}}{\tau_{c \alpha}^{\mathrm{g}}}-1\right)\right)\right)\right] \\
{\left[\frac{1}{2}\left(1+\operatorname{Tan} h\left(k \dot{\tau}_{\alpha}^{\mathrm{g}}\right)\right)\right]\left[\frac{1}{2}\left(1+\operatorname{Tanh}\left(k \tau_{\alpha}^{\mathrm{g}}\right)\right)\right]}
\end{gathered}
$$

where $H_{\alpha \alpha}^{\mathrm{gg}}$ is the self-hardening parameter defined in relation [15] and [16]. The hyperbolic tangent function was tested and used because it allows reproducing the mechanical and hardening behaviors.

By using [18] through [22], the slip rate on a system $g$ for the cell and wall regions becomes

$$
\begin{aligned}
\dot{\gamma}_{\mathrm{c}}^{\mathrm{g}}= & K_{\mathrm{c}}^{\mathrm{g}} R_{\mathrm{c}}^{\mathrm{g}}: \dot{\sigma}^{I I}+(1-f) K_{\mathrm{c}}^{\mathrm{g}} R_{\mathrm{c}}^{\mathrm{g}}: c:\left(I-s^{\mathrm{esh}}\right): \\
& \left.\sum_{\mathrm{h}} R_{\mathrm{w}}^{\mathrm{h}} \dot{\gamma}_{\mathrm{w}}^{\mathrm{h}}-\sum_{\mathrm{h}} R_{\mathrm{c}}^{\mathrm{h}} \dot{\gamma}_{\mathrm{c}}^{\mathrm{h}}\right) \\
\dot{\gamma}_{\mathrm{w}}^{\mathrm{g}}= & K_{\mathrm{w}}^{\mathrm{g}} R_{\mathrm{w}}^{\mathrm{g}}: \dot{\sigma}^{I I}+(1-f) K_{\mathrm{w}}^{\mathrm{g}} R_{\mathrm{w}}^{\mathrm{g}}: c:\left(I-s^{\mathrm{esh}}\right): \\
& \left.\sum_{\mathrm{h}} R_{\mathrm{w}}^{\mathrm{h}} \dot{\gamma}_{\mathrm{w}}^{\mathrm{h}}-\sum_{\mathrm{h}} R_{\mathrm{c}}^{\mathrm{h}} \dot{\gamma}_{\mathrm{c}}^{\mathrm{h}}\right)
\end{aligned}
$$

By developing [24] and [25], one obtains after calculations the following matrix form:

$$
\left(\begin{array}{c}
K_{\mathrm{c}}^{\mathrm{g}} R_{\mathrm{c}}^{\mathrm{g}}: \dot{\sigma}^{I I} \\
K_{\mathrm{w}}^{\mathrm{g}} R_{\mathrm{w}}^{\mathrm{g}}: \dot{\sigma}^{I I}
\end{array}\right)=\left(\begin{array}{cc}
\delta_{\mathrm{gh}}+(1-f) K_{\mathrm{c}}^{\mathrm{g}} R_{\mathrm{c}}^{\mathrm{g}}: c:\left(I-s^{\mathrm{esh}}\right): R_{\mathrm{c}}^{\mathrm{h}} & -(1-f) K_{\mathrm{c}}^{\mathrm{g}} R_{\mathrm{c}}^{\mathrm{g}}: c:\left(I-s^{\mathrm{esh}}\right): R_{\mathrm{w}}^{\mathrm{h}} \\
-f K_{\mathrm{w}}^{\mathrm{g}} R_{\mathrm{w}}^{\mathrm{g}}: c:\left(I-s^{\mathrm{esh}}\right): R_{\mathrm{c}}^{\mathrm{h}} & \delta_{\mathrm{gh}}+f K_{\mathrm{w}}^{\mathrm{g}} R_{\mathrm{w}}^{\mathrm{g}}: c:\left(I-s^{\mathrm{esh}}\right): R_{\mathrm{w}}^{\mathrm{h}}
\end{array}\right)\left(\begin{array}{c}
\dot{\gamma}_{\mathrm{c}}^{\mathrm{h}} \\
\dot{\gamma}_{\mathrm{w}}^{\mathrm{h}}
\end{array}\right)
$$

previous [19-21] conditions simultaneously. Processing time considerations become one of the main problems of the model. Moreover, this method could give several equivalent solutions for some hardening matrices. Franz et $a l .{ }^{[45]}$ proposed a different formulation to solve the problem of ambiguous selection of deformation systems and to reduce the computational processing time. Their numerical results in the case of BCC single crystals present a good agreement with the "classic" crystal plasticity based on the CRSS. This formulation was extended to the polycrystalline model framework by Lorrain et al. ${ }^{[46]}$ The accuracy of the simulations was also evaluated at the meso- and macroscopic levels by referring to mechanical experiments (tensile tests, neutron diffraction). Based on the work of Franz et al., ${ }^{[45]}$ the slip rate can be expressed by the following equation:

$$
\dot{\gamma}_{\alpha}^{\mathrm{g}}=K_{\alpha}^{\mathrm{g}} \dot{\tau}_{\alpha}^{\mathrm{g}}
$$

The slip rates $\left(\dot{\gamma}_{\mathrm{c}}^{\mathrm{g}}\right.$ and $\left.\dot{\gamma}_{\mathrm{w}}^{\mathrm{g}}\right)$ are linked to the resolved shear stress rates $\left(\dot{\tau}_{\mathrm{c}}^{\mathrm{g}}\right.$ and $\left.\dot{\tau}_{\mathrm{w}}^{\mathrm{g}}\right)$ through a function $K_{\alpha}^{\mathrm{g}}$. This function depends on $\tau_{\mathrm{c} \alpha}^{\mathrm{g}}$ and $\tau_{\alpha}^{\mathrm{g}}$. Hence, it is able to describe the hardening behavior during the plastic regime. The hardening parameter $K_{\alpha}^{\mathrm{g}}$ is given by where $\delta_{\text {gh }}$ is the Kronecker's delta. It should be noticed that superscripts $\mathrm{g}$ and $\mathrm{h}$ vary from 1 to $\mathrm{N}(N$ : number of active systems for each phase 'c' and ' $w$ ') for each term of the expression [26]. For clarity reason, the Eq. [26] is written in synthetic form: the variation of the superscript $\mathrm{g}$ and $\mathrm{h}$ is omitted. Equation [26] can be recast in a condensed form:

$$
\begin{gathered}
\left(\begin{array}{c}
K_{\mathrm{c}}^{\mathrm{g}} R_{\mathrm{c}}^{\mathrm{g}}: \dot{\sigma}^{I I} \\
K_{\mathrm{w}}^{\mathrm{g}} R_{\mathrm{w}}^{\mathrm{g}}: \dot{\sigma}^{I I}
\end{array}\right)=\left(\begin{array}{cc}
M_{\mathrm{cc}}^{\mathrm{gh}} & M_{\mathrm{cw}}^{\mathrm{h}} \\
M_{\mathrm{wc}}^{\mathrm{h}} & M_{\mathrm{ww}}^{\mathrm{h}}
\end{array}\right)\left(\begin{array}{c}
\dot{\gamma}_{\mathrm{c}}^{\mathrm{h}} \\
\dot{\gamma}_{\mathrm{w}}^{\mathrm{h}}
\end{array}\right) \\
\Leftrightarrow\left(\begin{array}{c}
\dot{\gamma}_{\mathrm{c}}^{\mathrm{g}} \\
\dot{\gamma}_{\mathrm{w}}^{\mathrm{g}}
\end{array}\right)=\left(\begin{array}{cc}
M_{\mathrm{cc}}^{\mathrm{gh}} & M_{\mathrm{cw}}^{\mathrm{h}} \\
M_{\mathrm{wc}}^{\mathrm{h}} & M_{\mathrm{ww}}^{\mathrm{h}}
\end{array}\right)^{-1} \times\left(\begin{array}{c}
K_{\mathrm{c}}^{\mathrm{g}} R_{\mathrm{c}}^{\mathrm{g}}: \dot{\sigma}^{I I} \\
K_{\mathrm{w}}^{\mathrm{g}} R_{\mathrm{w}}^{\mathrm{g}}: \dot{\sigma}^{I I}
\end{array}\right) \\
\Leftrightarrow\left\{\begin{array}{c}
\dot{\gamma}_{\mathrm{c}}^{\mathrm{g}}=T_{\mathrm{c}}^{\mathrm{g}}: \dot{\sigma}^{I I} \\
\dot{\gamma}_{\mathrm{w}}^{\mathrm{g}}=T_{\mathrm{c}}^{\mathrm{g}}: \dot{\sigma}^{I I}
\end{array}\right.
\end{gathered}
$$

Replacing the expressions of $\dot{\varepsilon}^{\mathrm{p} \alpha}$ (5) and $\dot{\gamma}_{\mathrm{c}}^{\mathrm{g}}$ [29] into [6], the following linear relation is obtained:

$$
\dot{\varepsilon}^{I I}=\left[s+\sum_{\mathrm{g}}\left(f R_{\mathrm{c}}^{\mathrm{g}}: T_{\mathrm{c}}^{\mathrm{g}}+(1-f) R_{\mathrm{w}}^{\mathrm{g}}: T_{\mathrm{w}}^{\mathrm{g}}\right)\right]: \dot{\sigma}^{I I}=\ell^{-1}: \dot{\sigma}^{I I}
$$


where $\ell^{-1}$ is the elastoplastic tangent stiffness tensor. This tensor depends on active systems, elastic properties, stress rate and deformation history of each phase.

When the loading direction is reversed (tension followed by compression, for example), the slip systems are active in the opposite direction and the dislocation microstructure is being reorganized. One obtains a more or less important dissolution of the cell structure, depending on the pre-strain rate. Therefore, a new dislocation arrangement is achieved. ${ }^{[35]}$ The hardening recovery is in line with the reconstruction of walls which dislocations having an opposite polarity to the pre-strain.

We introduced a dislocation densities law that captures the microstructural evolution during the reverse straining. For more details, the readers may refer to References 35, 47, 48. It was then considered that a part of dislocations was gradually annihilated during the reloading. Thus, the new expression for the total dislocation density, during the second load, is given by two terms $\rho_{\mathrm{fw}}^{\mathrm{h}}$ et $\rho_{\mathrm{rw}}^{\mathrm{h}}$ :

$$
\rho_{\mathrm{w}}^{\mathrm{h}}=\rho_{\mathrm{fw}}^{\mathrm{h}}+\rho_{\mathrm{rw}}^{\mathrm{h}}
$$

with $\rho_{\mathrm{fw}}^{\mathrm{h}}$, the dislocation density for the first loading. Its evolution is given by the Eqs. [7] through [8]. From the second loading, some of the dislocations are annihilated because of the change of loading path. This may then be simply expressed through the following relation:

$$
\rho_{\mathrm{fw}}^{\mathrm{h}}=(1-p) \rho_{\mathrm{fw}}^{0 \mathrm{~h}}
$$

$\rho_{\mathrm{fw}}^{0 \mathrm{~h}}$ is the dislocation density at the end of the first loading. $p$ presents the ratio of the annihilated dislocations during the second loading. $\rho_{\mathrm{fw}}^{\mathrm{h}}$ will continue to increase with strain rate.

$\rho_{\mathrm{rw}}^{\mathrm{h}}$ is the dislocation density reflecting the progressive dissolution of the microstructure during the second loading. Its initial value is calculated from

$$
\rho_{\mathrm{rw}}^{\mathrm{h}}=p \rho_{\mathrm{fw}}^{0 \mathrm{~h}}
$$

The rate evolution is considered as ${ }^{[47]}$

$$
\dot{\rho}_{\mathrm{rw}}^{\mathrm{h}}=-\frac{1}{b L^{\mathrm{g}}} \frac{\rho_{\mathrm{rw}}^{\mathrm{h}}}{\rho_{\mathrm{fw}}^{0 \mathrm{~h}}} \dot{\gamma}_{\mathrm{w}}^{\mathrm{h}}
$$

\section{B. Second Transition Scheme}

In this part, we deduce the global behavior from the local one. Hence, it will depend also on the hardening microstructure.

The relation between the stress rate $\left(\dot{\sigma}^{I}\right)$ and the strain rate $\left(\dot{\varepsilon}^{I}\right)$ can be written at the macroscopic scale as follows:

$$
\dot{\sigma}^{I}=\left\langle\dot{\sigma}^{I I}\right\rangle=\left\langle\ell: \dot{\varepsilon}^{I I}\right\rangle=L: \dot{\varepsilon}^{I}
$$

where $L$ is the macroscopic tangent modulus for the fictional average homogeneous medium.

The local strain and stress rates can be obtained classically through the localization A and concentration B tensors:

$$
\dot{\varepsilon}^{I I}=\left(I+S^{\mathrm{esh}}: L^{-1}: \Delta \ell\right)^{-1}: \dot{\varepsilon}^{I}=A: \dot{\varepsilon}^{I}
$$

and

$$
\begin{aligned}
\dot{\sigma}^{I I}=\ell & :\left(I+S^{\mathrm{esh}}: L^{-1}: \Delta \ell\right)^{-1}: L^{-1}: \dot{\sigma}^{I}=\ell: A: L^{-1} \\
: & \dot{\sigma}^{I}=B: \dot{\sigma}^{I}
\end{aligned}
$$

where $\Delta \ell=\ell-L$

The volume averages of the local stress and strain tensors must coincide with the overall strain and stress. After some algebraic calculations, these conditions give the overall elastoplastic tensor $L$ as a weighted average of the mesoscopic one $\ell$ :

$$
L=\left\langle\ell:\left[I+S^{e s h}: L^{-1}: \Delta \ell\right]^{-1}\right\rangle
$$

Equation [38] is a nonlinear implicit equation because $S^{\text {esh }}$ depends on the unknown $L$ in the framework of EPSC theory. The Eshelby tensor is calculated by an integral equation ${ }^{[24]}$ that fully takes into account the plastic anisotropy. This equation is solved iteratively. Once $L$ is known, by specifying an overall stress or strain increment, the model can give the corresponding stress or strain tensors for each orientation. Therefore, the mechanical response of the polycrystal can be described.

\section{RESULTS}

The performance of the enhanced approach presented above was verified for an AISI 316L austenitic stainless steel submitted to complex load paths. Different simulations of the global behavior at different pre-strains are presented. Then, the ability of the model to simulate correctly the different physical aspects of the local behavior and the induced microstructure during complex load paths is evaluated.

\section{A. Simulation Parameters}

In order to perform numerical simulations, the model parameters have to be identified:

- Isotropic and homogenous elasticity, described by shear modulus $\mu$ and Poisson's ratio $v$, is assumed (Table II).

- A value of 0.35 for $\xi$ (Eq. [10]) reflects multiple slips, involving the mutual intersection of dislocations of different slip systems. The cells are assumed to be ellipsoidal. The geometry of the cells is fixed during deformation whereas the dislocation densities will evolve (Eq. [7]). The texture was introduced in the model by a set of 1500 grains characterized by Euler 
Table II. Material Constants for 316L

\begin{tabular}{lccccc}
\hline $\mathrm{c}_{11}(\mathrm{MPa})$ & $\mathrm{c}_{12}(\mathrm{MPa})$ & $\mathrm{c}_{44}(\mathrm{MPa})$ & $b(\mathrm{~m})$ & $\rho_{0}\left(\mathrm{~m}^{-2}\right)$ & $y_{\mathrm{c}}(\mathrm{m})$ \\
\hline 245 & 105 & 70 & $5 \times 10^{-10}$ & $5 \times 10^{12}$ & $2.85 \times 10^{-9}$ \\
\hline
\end{tabular}

Table III. Simulation Parameters

\begin{tabular}{lcccccccccc}
\hline$\tau_{\mathrm{cc} 0}(\mathrm{MPa})$ & $\tau_{\mathrm{cw0}}(\mathrm{MPa})$ & $\zeta\left(\mathrm{MPa}^{2}\right)$ & $a^{\mathrm{gg}}$ & $a^{\mathrm{gh}}$ & $k_{\mathrm{L}}$ & $f_{0}$ & $f_{\infty}$ & $\gamma^{\mathrm{par}}$ & $\xi$ & $k$ \\
\hline 205 & 295 & 250 & 1 & 1.1 & 35 & 0.86 & 0.75 & 1.5 & 0.35 & 20 \\
\hline
\end{tabular}

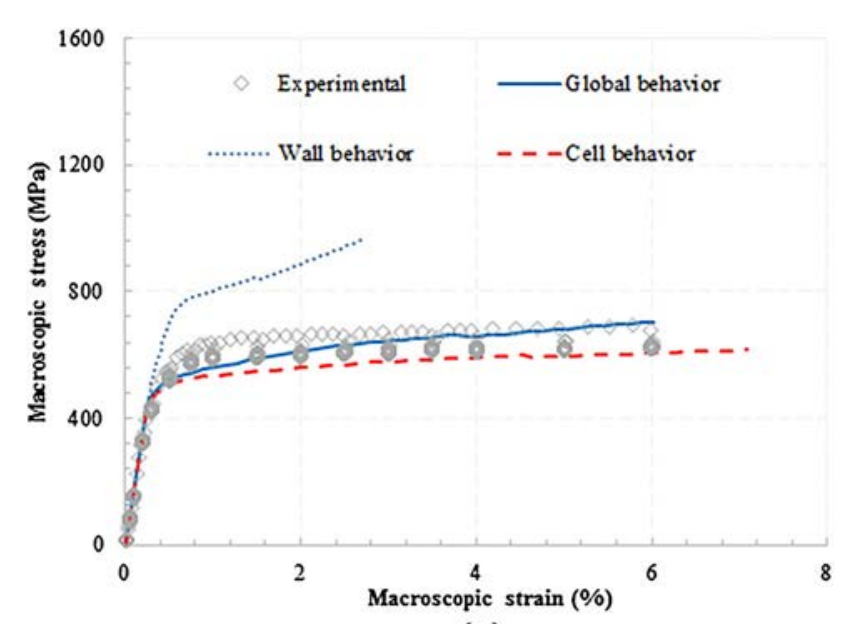

(a)

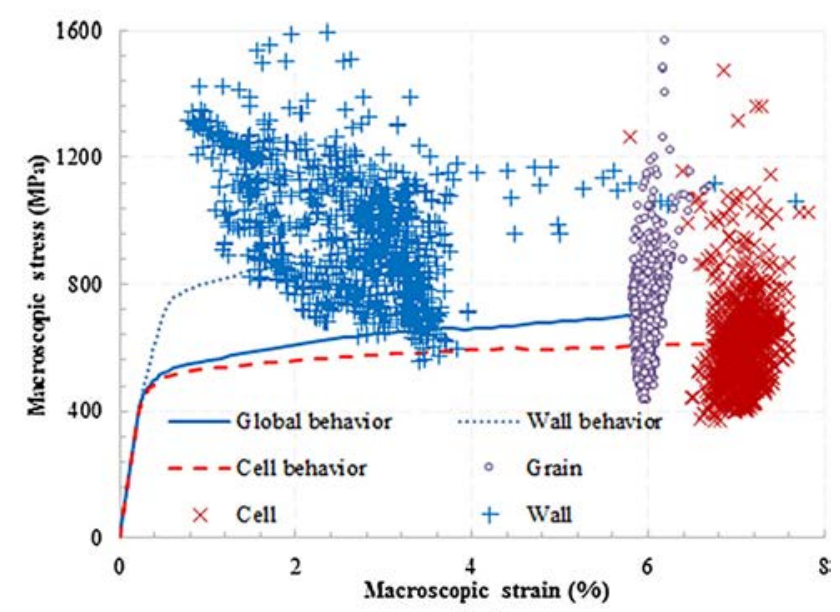

(b)

Fig. 5-(a) strain-stress responses of the austenitic sample under monotonic uniaxial tension: Experimental and simulated macroscopic results, and, the simulated phases behavior. (b) Scattered points represent the local strains and internal stresses heterogeneities.

angles and weights which represent their volume fraction. The number of crystallites has been chosen to simulate the polycrystalline aggregate in an efficient way.

- For FCC metals, the plastic deformation was modelled assuming $\{110\}\langle 111\rangle$ slip systems. Two different initials CRSS $\left(\tau_{\mathrm{cc} 0} \neq \tau_{\mathrm{wc} 0}\right)$ are taken for each deformation mode. These CRSS are deter- mined in order to reproduce the experimental yield stress.

- Only very few experimental results on the dislocations evolution are available. First, these values of parameters are chosen to be coherent with those given by the literature. After that, these parameters are adjusted so that the model gives a good fitting with the macroscopic experimental curve under monotonic deformation. This is justified since the parameters $\rho_{0}, y_{\mathrm{c}}$ (Eq. [8]), $k_{\mathrm{L}}$ (Eq. [9]) and $\xi$ (Eq. [13]) define the evolution of the dislocation density and the hardening behavior. Therefore, they can be derived from the macroscopic behavior. To determine the volume fraction, typical values for cell regions observed at small to moderate deformations are adopted. ${ }^{[34]}$ The $\mathrm{k}$ value (Eq. [23]) for each material is determined by comparison with a classic EPSC model under monotonic deformation (in term of main active deformation systems, crystal reorientations). Simulation parameters are summarized in Table III.

\section{B. Global Behavior}

Our validation starts by reproducing the global mechanical behavior of AISI 316L austenitic stainless steel during the uniaxial loading. This first simulation allows to study the effect of a monotonic tension test $(6$ pct) on the evolution of wall and cell behaviors, but also on the variation of internal stress heterogeneity (Figures 5(a) and (b)).

The stress-strain curve obtained with the present model two-level homogenization (2LH) and the experimental one for the first loading are compared in Figure 5(a). The elastic part is correctly simulated despite the elastic isotropy assumption in the single crystal. In the plastic part, the material has a very low hardening slope characterized by a rapid elastoplastic transition. The initial residual stresses in the as-received non-loaded sample explain this type of hardening.

In our simulation, it is difficult to reproduce exactly this behavior without introducing numerical instabilities in the calculation of the overall elastoplastic tangent moduli L (Eq. [38]). A compromise was found by increasing the simulated hardening rate in two steps, up to 2 pct and then up to 6 pct. Then, the stress-strain curve is well reproduced throughout the elastoplastic part of the first loading. 
Figure 5(a) displays the internal mechanical behavior within cells and walls:

$$
\sigma_{11}^{\alpha}=\sum_{n} f_{n} \sigma_{11}^{n \alpha} \quad \text { and } \quad \varepsilon_{11}^{\alpha}=\sum_{n} f_{n} \varepsilon_{11}^{n \alpha}
$$

where $f_{n}$ represents the volume fraction of grain $n$.

It can be observed that the polycrystal and the phases do not reach their yield limit at the same time: cells and walls do not have the same initial CRSS. The wall hardening is controlled by the plasticity of the cells (Eqs. [8] and [11]). Therefore, the wall behavior becomes harder than the cell one.

Figure 5(b) shows simultaneously the third-order stresses $\sigma_{11}^{n \alpha}$ for each phase and the resulting mesoscopic stresses $\sigma_{11}^{I I}$ at the grain level just before the elastic unloading. This description allows to reveal the strong internal stresses induced in walls phase and the development of heterogeneities during plastic regime. The dislocation density in walls increases more than the one inside cells. The internal stress differences as well as the induced yield stresses are due to this phenomenon.

Figure 6 presents the experimental and predicted results of the tension-compression tests at two prestrains: 2 and 6 pet for the $2 \mathrm{LH}$ model and the $1 \mathrm{LH}$ approach (one level homogenization using an EPSC model).

In the $1 \mathrm{LH}$ model, the grain is considered as a uniform medium. The intragranular heterogeneities are neglected or taken into account through the matrix hardening in a phenomenological way. In the present work, the model developed in Reference 49 is used. For a more detailed description of the EPSC model, see

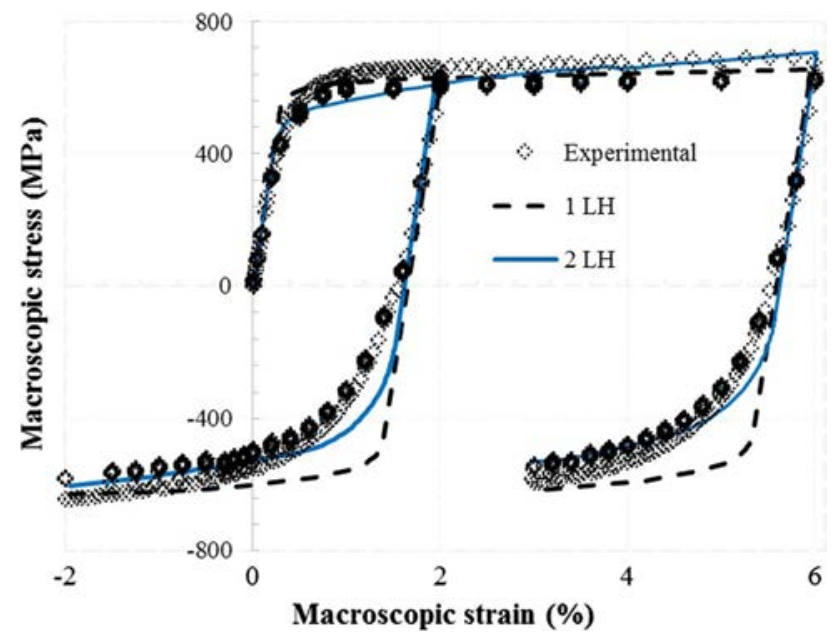

Fig. 6-Comparison between experimental and simulated stressstrain curves during complex load path.
References 24, 50. Each grain is assumed to have the form of an ellipsoidal inclusion in a homogeneous effective medium whose properties are the average of all the other grains in the assembly.

The 1 LH approach reproduces the macroscopic mechanical behavior under monotonic loading. But the EPSC scheme fails to explain and reproduce correctly the softening effects during the compression loading. Indeed, during the second loading, significant dispersions are observed with this model: at 1.25 pct of total strain, the predicted longitudinal stress value reaches $\sigma_{11}^{I}=-526 \mathrm{MPa}$ when the experimental one is only $-185 \mathrm{MPa}$.

One can observe that the 2 LH model captures all the essential features (reloading yield stress, macroscopic work hardening) associated with the Bauschinger effect. However, during an elastoplastic transition, dispersion is noticed. At 2 pct of prestrain rate, the maximum standard deviation reaches 20 pct when it is only 13 at 6 pct of prestrain rate. For the highest prestrain rate, the difference between experimental and numerical results becomes small. This can be explained by the fact that the initial hardening of the material has a stronger influence for a low rate of prestrain. For a 6 pct prestrain rate, the loading clears the hardening history. This phenomenon is partially taken into account in our approach.

\section{Internal Strain Response}

In order to validate the elastoplastic constitutive law, the numerical results are compared with experimental ones obtained on the ENGIN-X diffractometer. The internal strain development in different grain orientations can be used as a useful and sensitive sensor of plasticity. Thus, the $2 \mathrm{LH}$ was tested also at diffracting volume scale. Longitudinal and transverse strains are

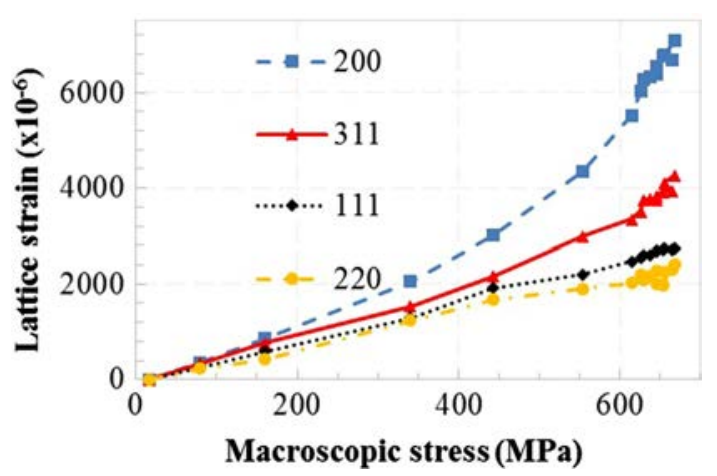

Fig. 7-Evolution of longitudinal lattice strain, for various reflections, as a function of applied stress during the first loading.

Table IV. Maximal Experimental Error Bars of hkl Reflection Families for Each Sample

\begin{tabular}{lcccccccc}
\hline Prestrain $(\mu$ def $)$ & $\{111\}$ & $\{200\}$ & $\{220\}$ & $\{311\}$ & $\{331\}$ & $\{420\}$ & $\{422\}$ & $\{511\}$ \\
\hline Sample 1: 2 pct & 21 & 42 & 153 & 75 & 288 & 349 & 402 & 263 \\
Sample 2: 6 pct & 21 & 42 & 127 & 70 & 329 & 176 & 264 & 202 \\
\hline
\end{tabular}


\{111\}

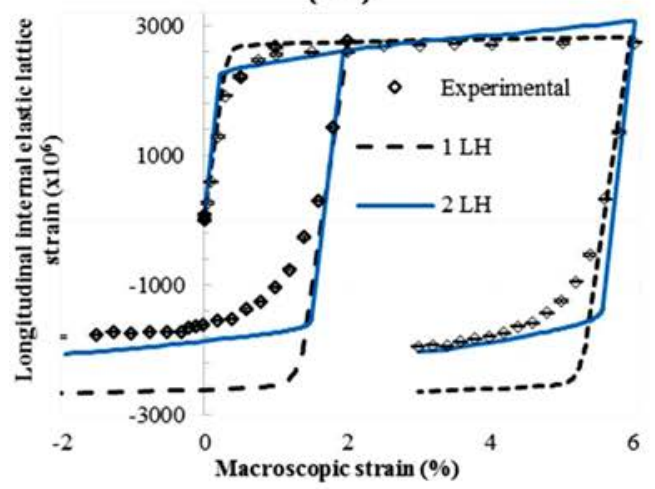

\{200\}

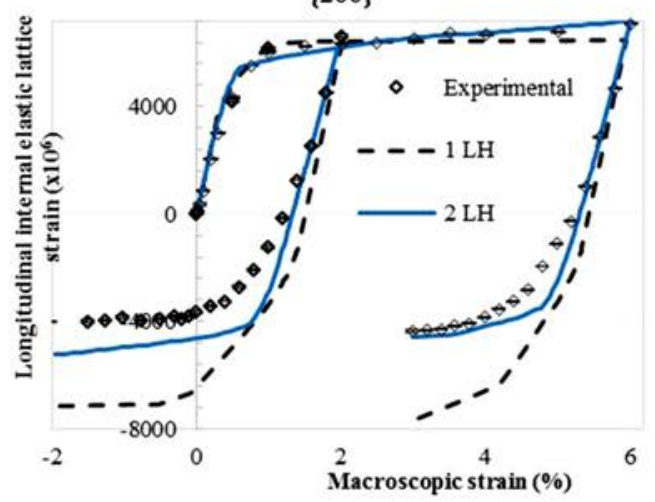

\{220\}

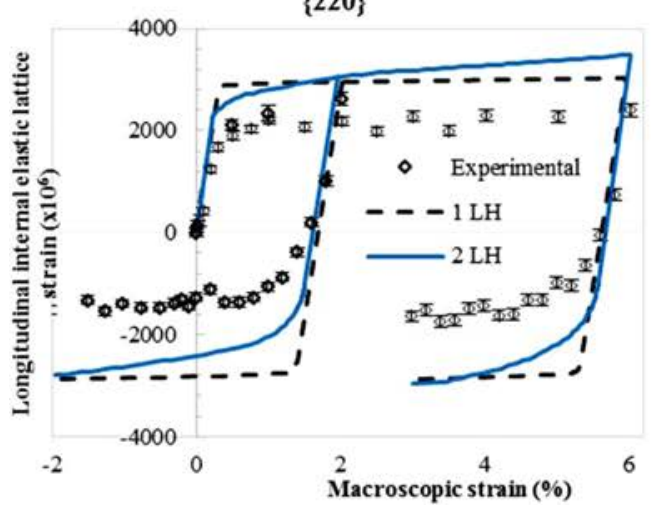

\{311\}

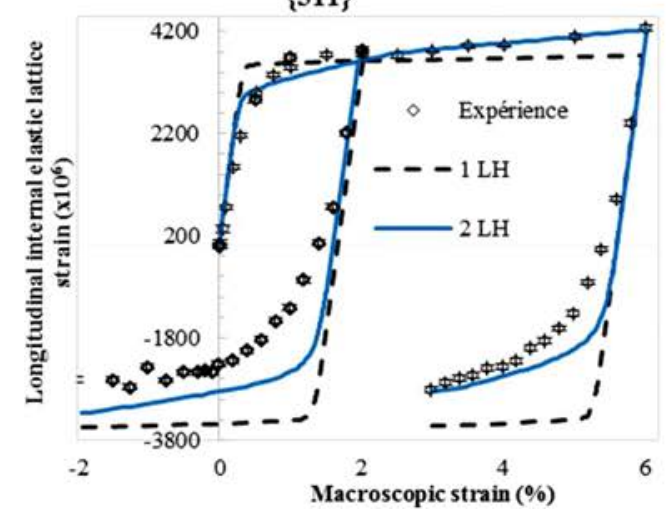

\{111\}

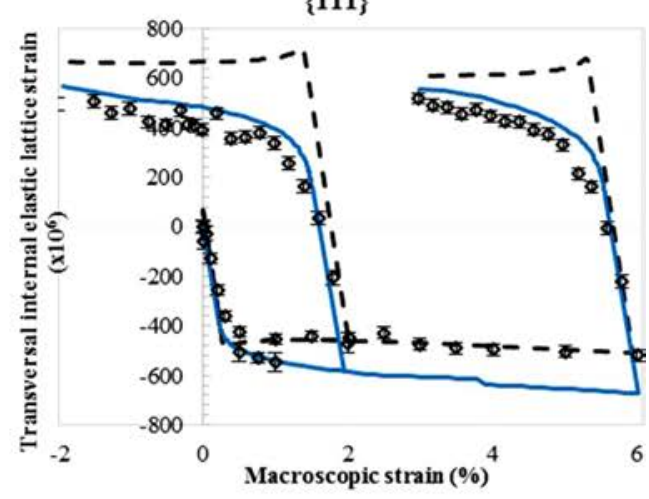

\{200\}

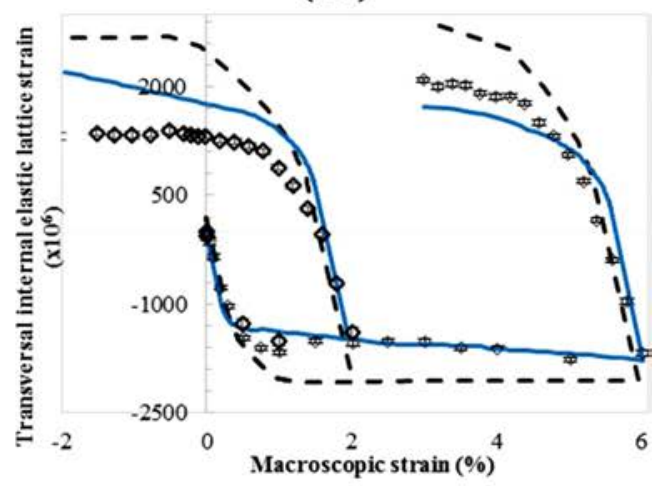

$\{220\}$

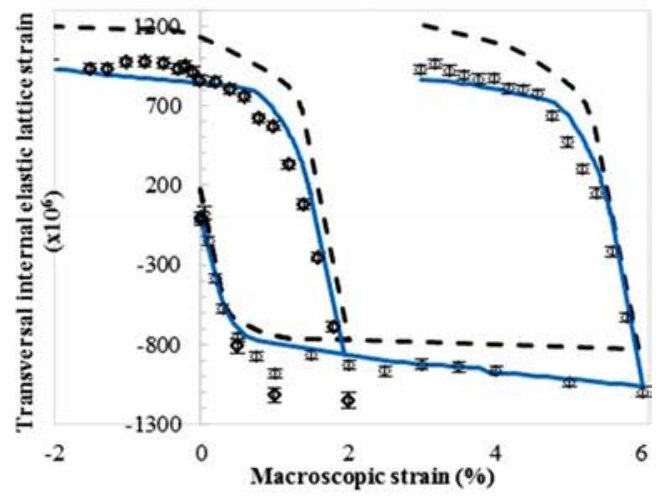

$\{200\}$

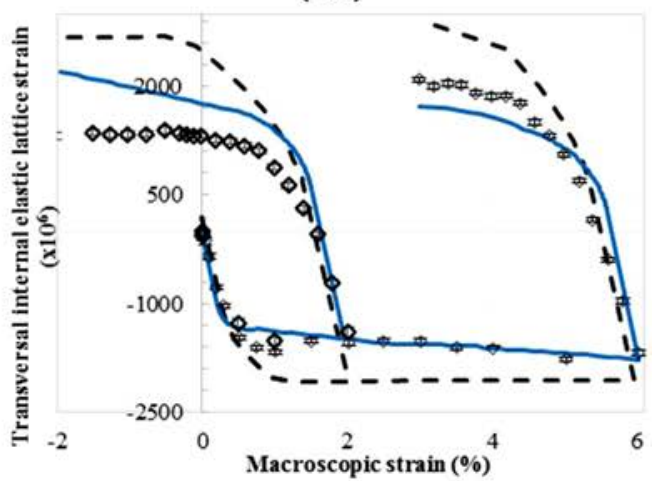

Fig. 8-Evolution of the elastic lattice strain along various directions as a function of the global strain.

simulated for four hkl reflections (statistically representative): 111, 200, 220 and 311. The behavior simulation of diffracting volume is made with the same parameters as those used to simulate the overall one (Table III). A comparison is performed between the $1 \mathrm{LH}$ simulations and the present model at the diffracting volume. 
The development of the measured longitudinal and transverse internal strains during tensile-compression test is shown in Figure 5 for all the studied hkl reflections. It can be observed that there is a large variability in terms of the strain evolution, depending on the analysed diffracting plane and because of the plastic anisotropy in austenitic stainless steel. According to the analysed plane families, each crystallites group has different crystallographic orientations controlled by the initial texture of the material. These groups were more or less deformed depending on their orientation in relation to the loading axis, inducing the results variability for the measured lattice strains.

For example, in plasticity, the $\{200\}$ orientation undergoes more stresses (hard slip) when the other planes families plasticize. On the other hand, the 111 reflection undergoes less stress; therefore it corresponds to a group of more ductile crystallites (easy slip). To illustrate this analysis, the evolution of the internal strain versus the macroscopic strain is plotted (Figure 7).

Error bars are mainly dependent of the considered hkl reflections. Table IV clearly shows that these errors are large especially for 331, 420, 422 and 511. The smallest error is $21 \mu$ strain for the 111 reflection and the higher one is $402 \mu$ strain for the 422 reflection. It can be observed that, between both stress values 2 and 6 pct, the uncertainties are not in the same order of magnitude for a considered hkl reflection. For example, the difference reaches $138 \mu$ strain for the 422 reflection.

During the first loading and for the longitudinal and transverse directions, a good agreement between the simulated curves and the experimental points in the elastic and plastic regimes under both approaches (1 LH and $2 \mathrm{LH}$ ) can be seen. The standard deviations between the experimental and simulated points vary from 0 to 33 pct (Figure 8 ). The maximum value is noticed for the 220 reflection.

During the load path change and for the longitudinal direction, the two-level homogenization approach (2 LH) better reproduces the experimental results than the EPSC model (1 LH) whatever the crystallographic reflection. At the end of the compression loading, the standard deviation between the two models is 27 pct for the longitudinal response of the 111 reflection.

The $1 \mathrm{LH}$ approach fails to reproduce correctly the longitudinal elastic lattice strain during the second loading. Significant differences are obtained compared to the experimental results showing a significant standard deviation (52 pct). In this model, the local behavior (at the grain level) is based on the assumption of uniform deformation neglecting the formation of the dislocation microstructure. Moreover, this microstructure has an important role during the second loading.

It should be noted that for the $2 \mathrm{LH}$ results, a good correlation with the experimental results is obtained; the transverse lattice strain for almost all reflections are well reproduced. Apart from the 220 reflection, weak standard deviations are obtained varying from 0 to 20 pct. Moreover, the model gives the higher standard deviation for the 220 reflection with a value of 40 pct. It should be noticed that the response in the transverse direction is very sensitive to the crystallographic texture and that the measured strain value is the average over a set of grains. Therefore, this can explain the difficulty to reproduce the results obtained in this direction. However, one could conclude that the developed approach gives good results for this direction.

Generally, despite some theoretical and experimental assumptions (isotropic elasticity, initial residual stress, microstructure heterogeneities), the model is able to reproduce the lattice strain evolution for the studied material. The largest tensile strains are observed for the $\{200\}$ plane family. Thus, this grain group undergoes more stress when another one plasticizes and therefore has higher yield strength (Figure 7). On the other hand, the 111 reflection undergoes less stress. It represents the more ductile family because the corresponding crystallite group is friendly oriented with respect to the loading direction. For the diffracting volume, the Bauschinger effect is better reproduced in the transverse direction than in the longitudinal one. It can be observed that some planes families are very sensitive like the $\{220\}$ and the $\{331\}$ planes.

\section{CONCLUSION}

In this work, a new approach based on a two-level transitions model was validated using in situ neutron diffraction data, acquired under sequential loadings on the ENGIN-X beamline at the ISIS facility. Moreover, the developed model was compared to the single-scale transition model usually used. Evolution of the longitudinal and transverse internal strains was determined during Bauschinger tests.

The single-level transition, using the self-consistent model, matches correctly the experimental results during the first loading for the macroscopic behavior. Nevertheless, this model fails to capture the elastoplastic transition during the second loading as it does not take into account the evolution of the microstructure of dislocation.

The developed model is based on a two-level transition approach. The grain is considered as a two-phase material with cell walls (with high dislocation density) and cell interiors (with low dislocation density). A mechanical description of the grain is expanded through a micro-meso transition based on a Kröner modified approach. The intragranular heterogeneities are described by a non-local work-hardening linked to the two-phase description. The dissolution of the dislocation microstructure is also implemented. This consideration for the microstructure description allows to better reproduce the local and global mechanical behaviors for the analysed reflections.

The presented composite grain approach, coupled with a non-local hardening and a dislocation densities evolution law, is well adapted. It highlights the Bauschinger effect characterized among others by an early re-yielding during reverse deformation. 


\section{REFERENCES}

1. A.A. Saleh, E.V. Pereloma, B. Clausen, D.W. Brown, C.N. Tomé, and A.A. Gazder: Acta Mater., 2013, vol. 61, pp. 5247-62, DOI:10.1016/j.actamat.2013.05.017.

2. D. Gloaguen, G. Oum, V. Legrand, J. Fajoui, and S. Branchu: Acta Mater., 2013, vol. 61, pp. 5779-90, DOI:10.1016/j.actamat.2013.06.022.

3. J. Fajoui, D. Gloaguen, B. Courant, and R. Guillén: Comput. Mech., 2009, vol. 44, pp. 285-96, DOI:10.1007/s00466-009-0374-7.

4. D. Muller, X. Lemoine, and M. Berveiller: J. Eng. Mater. Technol., 1994, vol. 116, pp. 378-83, DOI:10.1115/1.2904301.

5. D. Muller, M. Berveiller, and J. Kratochvíl: Mater. Sci. Forum., 1993, vols. 123-125, pp. 195-204, DOI:10.4028/www.scientific.net/ MSF.123-125.195.

6. X. Feaugas, P. Pilvin, and M. Clavel: Acta Mater., 1997, vol. 45, pp. 2703-714, DOI:10.1016/S1359-6454(96)00407-7.

7. P. Evrard, I. Alvarez-Armas, V. Aubin, and S. Degallaix: Mech. Mater., 2010, vol. 42, pp. 395-404, DOI:10.1016/j.mechmat.2010.01.007.

8. Y. Li, V. Aubin, C. Rey, and P. Bompard: Int. J. Fatigue., 2012, vol. 42, pp. 71-81, DOI:10.1016/j.ijfatigue.2011.07.003.

9. T. Skippon and M.R. Daymond: Mater. Sci. Eng. A., 2015, vol. 634, pp. 77-85, DOI:10.1016/j.msea.2015.03.033.

10. B. Haddag, T. Balan, and F. Abed-Meraim: Int. J. Plast., 2007, vol. 23, pp. 951-79, DOI:10.1016/j.ijplas.2006.10.004

11. S. Mahesh, C.N. Tomé, R.J. McCabe, G.C. Kaschner, A. Misra, and I.J. Beyerlein: Metall. Mater. Trans. A., 2004, vol. 35A, pp. 3763-74, DOI:10.1007/s11661-004-0282-6.

12. S. Hiwatashi, A. Van Bael, P. Van Houtte, and C. Teodosiu: Comput. Mater. Sci., 1997, vol. 9, pp. 274-84, DOI:10.1016/S09270256(97)00069-4.

13. H. Mughrabi: Phys. Status Solidi A., 1987, vol. 104, pp. 107-120, DOI:10.1002/pssa.2211040108.

14. B. Peeters, M. Seefeldt, C. Teodosiu, S.R. Kalidindi, P. Van Houtte, and E. Aernoudt: Acta Mater., 2001, vol. 49, pp. 1607-19, DOI:10.1016/S1359-6454(01)00066-0.

15. J. Fajoui, D. Gloaguen, and B. Girault: Acta Mech., 2015, vol. 226, pp. 2715-27, DOI:10.1007/s00707-015-1347-x.

16. I. Karaman, H. Sehitoglu, A.J. Beaudoin, Y.I. Chumlyakov, H.J. Maier, and C.N. Tomé: Acta Mater., 2000, vol. 48, pp. 2031-2047, DOI: 10.1016/S1359-6454(00)00051-3.

17. E.M. Viatkina, W.A.M. Brekelmans, and M.G.D. Geers: Comput. Mech., 2008, vol. 41, pp. 391-405, DOI:10.1007/s00466-007-0195-5.

18. M. Knezevic, R.J. McCabe, R.A. Lebensohn, C.N. Tomé, C. Liu, M.L. Lovato, and B. Mihaila: J. Mech. Phys. Solids., 2013, vol. 61, pp. 2034-46, DOI:10.1016/j.jmps.2013.05.005.

19. G. Franz, F. Abed-Meraim, and M. Berveiller: Int. J. Plast., 2013, vol. 48, pp. 1-33, DOI:10.1016/j.ijplas.2013.02.001.

20. H. Mughrabi: Acta Metall., 1983, vol. 31, pp. 1367-79, DOI:10.1016/0001-6160(83)90007-X.

21. X. Lemoine, M. Berveiller, and D. Muller: Mater. Sci. Forum., 1994, vols. 157-162, pp. 1821-26, DOI:10.4028/www.scientific.net/ MSF.157-162.1821.

22. F. David, I. Aubert, X. Lemoine, and M. Berveiller: Comput. Mater. Sci., 1997, vol. 9, pp. 188-198, DOI:10.1016/S09270256(97)00074-8.

23. D. Gloaguen, M. Francois: Phys. Status Solidi Appl. Mater. Sci. 203 (2006) 1940-1953. http://cat.inist.fr/?aModele = afficheN\& cpsidt $=17860381$ (accessed September 3, 2014).

24. P. Lipinski and M. Berveiller: Int. J. Plast., 1989, vol. 5, pp. 149-72, DOI:10.1016/0749-6419(89)90027-2.

25. P.D. Wu, S.R. MacEwen, D.J. Lloyd, M. Jain, P. Tugcu, and K.W. Neale: J. Plast., 2005, vol. 21, pp. 723-39, DOI:10.1016/ j.ijplas.2004.05.007.
26. M. Choteau, P. Quaegebeur, and S. Degallaix: Mech. Mater., 2005, vol. 37, pp. 1143-52, DOI:10.1016/j.mechmat.2004.12.001.

27. A.S. Keh and Y. Nakada: Can. J. Phys., 1967, vol. 45, pp. 1101-120, DOI:10.1139/p67-081.

28. D. Gloaguen, J. Fajoui, and B. Girault: Acta Mater., 2014, vol. 71, pp. 136-44, DOI:10.1016/j.actamat.2014.02.031.

29. R. Dakhlaoui, V. Klosek, M.H. Mathon, and B. Marini: Acta Mater., 2010, vol. 58, pp. 499-509, DOI:10.1016/j.actamat.2009.09.028.

30. R. Dakhlaoui, A. Baczmański, C. Braham, S. Wroński, K. Wierzbanowski, and E.C. Oliver: Acta Mater., 2006, vol. 54, pp. 5027-39, DOI:10.1016/j.actamat.2006.06.035.

31. J.R. Santisteban, M.R. Daymond, J.A. James, and L. Edwards: $J$. Appl. Crystallogr., 2006, vol. 39, pp. 812-25, DOI:10.1107/ S0021889806042245.

32. C.M. Moreton-Smith, S.D. Johnston, and F.A. Akeroyd: $J$. Neutron Res., 1996, vol. 4, pp. 41-47, DOI:10.1080/10238169608 200066.

33. W. Kockelmann, L.C. Chapon, and P.G. Radaelli: Neutron texture analysis on GEM at ISIS, in: Phys. B Condens. Matter, Elsevier, 2006: pp. 639-43. http://cat.inist.fr/?aModele $=$ affiche N\&cpsidt $=18370454$ (accessed September 3, 2014).

34. X. Feaugas: Acta Mater., 1999, vol. 47, pp. 3617-32, DOI:10.1016/ S1359-6454(99)00222-0.

35. G. Vincze, E.F. Rauch, J.J. Gracio, F. Barlat, and A.B. Lopes: Acta Mater., 2005, vol. 53, pp. 1005-13, DOI:10.1016/j.actamat.2004.10.046.

36. K.E. Zur: Acta Metall., 1961, vol. 9, pp.155-61. http://www. refdoc.fr/Detailnotice?idarticle.

37. C. Schmitt, P. Lipinski, and M. Berveiller: Int. J. Plast., 1997, vol. 13, pp. 183-99, DOI:10.1016/S0749-6419(95)00007-0.

38. D. Gloaguen, M. François, and R. Guillen: J. Appl. Crystallogr., 2004, vol. 37, pp. 934-40, DOI:10.1107/S0021889804022034.

39. J.D. Eshelby: Proc. R. Soc. Lond. Ser. Math. Phys. Sci., 1957, vol. 241, pp. 376-96, DOI:10.1098/rspa.1957.0133.

40. M. Berveiller and A. Zaoui: J. Mech. Phys. Solids., 1978, vol. 26, pp. 325-44, DOI:10.1016/0022-5096(78)90003-0.

41. C. Beradai, M. Berveiller, and P. Lipinski: Int. J. Plast., 1987, vol. 3, pp. 143-62, DOI:10.1016/0749-6419(87)90004-0.

42. E. Nes: Prog. Mater. Sci., 1997, vol. 41, pp. 129-93, DOI:10.1016/ S0079-6425(97)00032-7.

43. U. Essmann and H. Mughrabi: Philos. Mag. A., 1979, vol. 40, pp. 731-56, DOI:10.1080/01418617908234871.

44. P. Franciosi: Acta Metall., 1985, vol. 33, pp. 1601-612, DOI:10.1016/0001-6160(85)90154-3.

45. G. Franz, F. Abed-Meraim, J.-P. Lorrain, T. Ben Zineb, X. Lemoine, and M. Berveiller: Int. J. Plast., 2009, vol. 25, pp. 205-238, DOI:10.1016/j.ijplas.2008.02.006.

46. J.-P. Lorrain, T. Ben-Zineb, F. Abed-Meraim, and M. Berveiller: Int. J. Form. Process., 2005, vol. 8, pp. 135-58, DOI:10.3166/ ijfp.8.135-158.

47. E.F. Rauch, J.J. Gracio, and F. Barlat: Acta Mater., 2007, vol. 55, pp. 2939-48, DOI:10.1016/j.actamat.2007.01.003.

48. K. Kitayama, C.N. Tomé, E.F. Rauch, J.J. Gracio, and F. Barlat: Int. J. Plast., 2013, vol. 46, pp. 54-69, DOI:10.1016/j.ijplas.2012.09.004.

49. D. Gloaguen, M. Francois, R. Guillen, J. Royer: Acta Mater. 50 (2002) 871-880. http://cat.inist.fr $/$ ?aModele $=$ afficheN\&cpsidt $=$ 13481335 (accessed September 12, 2014).

50. D. Gloaguen, G. Oum, V. Legrand, J. Fajoui, M.-J. Moya, and T. Pirling: Metall. Mater. Trans. A., 2015, vol. 46A, pp. 5038-46, DOI:10.1007/s11661-015-3073-3.

51. L. Lutterotti, S. Matthies, and H.R. Wenk: in Proceeding Twelfth Int. Conf. Textures Mater. ICOTOM-12, NRC Press Ottawa, Canada, 1999, p. 1599. 